\title{
Article \\ The Efficiency of Biocidal Silica Nanosystems for the Conservation of Stone Monuments: Comparative In Vitro Tests against Epilithic Green Algae
}

\author{
Flavia Bartoli *(D), Martina Zuena (D), Armida Sodo (D) and Giulia Caneva (D) \\ Dipartimento di Scienze, Università degli Studi "Roma Tre", 00146 Roma, Italy; \\ martina.zuena@uniroma3.it (M.Z.); armida.sodo@uniroma3.it (A.S.); giulia.caneva@uniroma3.it (G.C.) \\ * Correspondence: flavia.bartoli@uniroma3.it; Tel.: +39-06-5733-6374; Fax: +39-06-573-36321
}

Citation: Bartoli, F.; Zuena, M.; Sodo, A.; Caneva, G. The Efficiency of Biocidal Silica Nanosystems for the Conservation of Stone Monuments: Comparative In Vitro Tests against Epilithic Green Algae. Appl. Sci. 2021, 11, 6804. https://doi.org/10.3390/ app11156804

\section{Academic Editors: Maria}

Filomena Macedo, António Manue Santos Carriço Portugal, Ana Miller and Ana Catarina Pinheiro

Received: 29 May 2021

Accepted: 21 July 2021

Published: 24 July 2021

Publisher's Note: MDPI stays neutra with regard to jurisdictional claims in published maps and institutional affiliations.

Copyright: (c) 2021 by the authors. Licensee MDPI, Basel, Switzerland. This article is an open access article distributed under the terms and conditions of the Creative Commons Attribution (CC BY) license (https:// creativecommons.org/licenses/by/ $4.0 /)$.

\begin{abstract}
In the last decade, worldwide research has focused on innovative natural biocides and the development of organic and inorganic nanomaterials for long-lasting reliability. In this work, the biocide effects of two different biocides encapsulated in two different silica nanosystems for a multifunctional coating have been performed through in vitro tests, by using Chlorococcum sp. as a common stone biodeteriogen. Zosteric sodium salt (ZS), a green biocide, was compared with the commercial biocide, 2-mercaptobenzothiazole (MBT), widely used in the treatment of cultural heritage. The analyzed systems are the following: silica nanocapsules (NC) and silica nanoparticles (MNP) not loaded with biocides, two nanosystems loaded with ZS and MBT, and free biocides. The qualitative and quantitative evaluations of biocide efficiency were performed periodically, analyzing pigment autofluorescence to discriminate between active and inactive/dead cells. The analyses showed multiple differences. All the nanocontainers presented an initial reduction in chlorophyll's autofluorescence. For the free biocide, the results highlighted higher efficiency for MBT than ZS. Finally, the nanosystems loaded with the different biocides highlighted a higher activity for nanocontainers loaded with the commercial biocide than the green product, and better efficiency for MNP in comparison with NC.
\end{abstract}

Keywords: cultural heritage; multifunctional coating; stone biodeterioration; biofilms; biocide; zosteric sodium salt; 2-mercaptobenzothiazole; silica nanosystems

\section{Introduction}

Cultural heritage artworks have an inestimable value that must be protected and preserved to be passed on to future generations. They are affected by different alteration processes and degradation, which increase over time, and in outdoor conditions, they are exposed to a greater extent of atmospheric agents as well as to biological colonization [1-3].

Thanks to technological advancements in recent times, applied techniques and the biocide products used to remove biofilms on monument surfaces have been improved [4-8]. Biocides are chemical substances which are efficient at killing the undesirable microorganisms that can occur on such surfaces, and they have been widely applied in the conservation of cultural heritage [9-11]. However, traditional commercial biocide can show some harmful effects on the environment and human health; furthermore, they can also show some interferences with the substrate, such as staining, changes in color, and chemical interactions $[8,10,12]$. Application methods and low doses can reduce the mentioned risks. Moreover, the direct application of biocide has relatively short-term effectiveness, and sometimes, the compounds can be removed and dispersed in the environment $[2,8,10,13]$.

In the last decade, worldwide research has concerned the testing of innovative natural biocide and the development of organic and inorganic nanomaterials, associated with multifunctional coatings, for long-lasting reliability, and non-invasive and selective 
activity [7,8,13-24]. The use of natural active compounds coupled to this nanotechnology seems a good way to pursue an eco-friendly, sustainable, and safe approach for the conservation of cultural heritage, reducing the amount of the bioactive compound and obtaining a satisfactory, long-lasting, antifouling action [15-17,25-27]. The literature reports the synthesis of different nanocontainers and loading techniques [21,25]. However, nanosystems based on mesoporous silica materials, applied in a multifunctional coating, as a controlled release biocide system over time, are reported only in a few cases $[19,21,28-30]$. In previous works, two different silica-based nanocontainers (Ns), namely a core-shell nanocapsule (NC) and a mesoporous nanoparticle (MNP), have been synthesized and characterized [13,14,20-22]. Previous preliminary in vitro cultures exposed to the nanoparticles showed a high antifouling activity associated with a slight biocidal activity against photosynthesizing microorganisms [13]. However, the efficiency of these Ns in the release control of the engaged biocides and the improvement of biocide efficiency, allowing a reduction in the quantities of biocide required, have not been sufficiently addressed.

In this work, our goal is to test different biocidal agents through in vitro tests against a significant component of the biofilm occurring on stone in conditions of high humidity and low solar radiation, and in parallel, evaluating different coatings' formulations. According to ecological trends and EU regulations [31], we tested natural zosteric sodium salt, a derivative of zosteric acid, as a natural antifoulant compound, in comparison with the commercial biocide 2-mercaptobenzothiazole widely used in the treatment of cultural heritage $[9,32,33]$. The choice of both biocides and, in particular, of zosteric sodium salt as a green biocide, despite the possibility of a negative effect being linked to sulfate residues [34], is related to the previous results for the nanocontainers' synthesis [13,14,20-22]. Such a first step will need further evaluation before a wider application.

\section{Materials and Methods}

\subsection{Biocidal Description}

We selected two different biocides, namely 2-mercaptobenzothiazole and zosteric sodium salt. 2-mercaptobenzothiazole (MBT) is a well-known biocide used in the conservation of cultural heritage as an antifungal and anticryptogamical compound [9]. From the literature data, the biocidal activity of MBT is linked to its heterocyclic structure, and the substituted benzothiazole derivatives bring different biological properties $[35,36]$.

Zosteric sodium salt (ZS) is a natural product antifoulant (NPA), which is less studied, but a promising product in this context. Zosteric acid and its sodium salt are produced and released by Zostera marina L., which is a wide-ranging marine flowering plant in the Northern Hemisphere, and its antifouling capability is related to the sulfate group present in the chemical structure [37].

As reported in Ruggiero et al. [20], we synthesized ZS from trans-4-hydroxycinnamic and the sulfur trioxide pyridine complex.

\subsection{Encapsulation Step}

According to Ruggiero et al. [20,21], we synthesized two different silica nanocontainers, namely core-shell nanocapsules (NC) and mesoporous nanoparticles (MNP) (Figure 1). Briefly, to synthesize the silica nanocapsules (NC), the following compounds were adopted: water, cetyltrimethylammonium bromide (CTAB, Aldrich, Italy) as a cationic surfactant, ammonia solution (NH3aq 30\%, Aldrich) as a basic catalyst, tetraethoxysilane (TEOS, Aldrich) as a silica precursor, and diethyl ether (Et2O, Aldrich) as a cosolvent. All the chemicals were analytical grade and were used without further purification. 
[a]

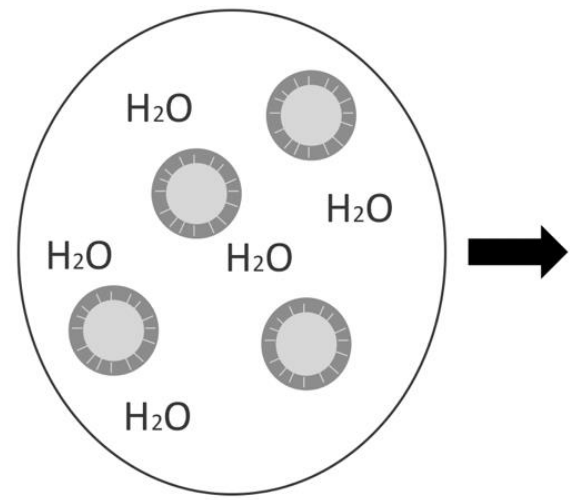

Silica nanocapsule $(\mathrm{NC})$

[b]

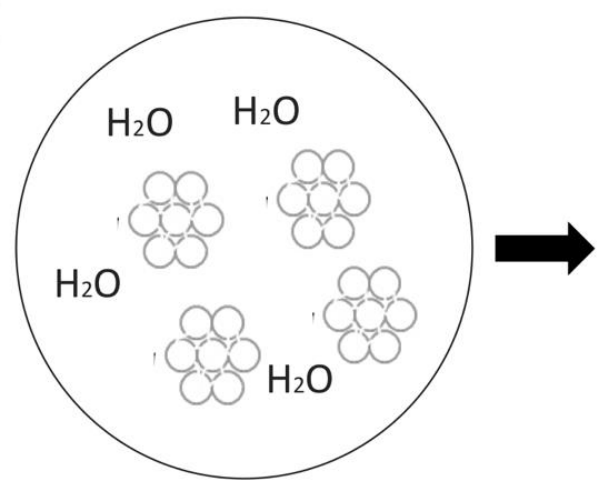

Mesoporous silica nanoparticles (MNP)

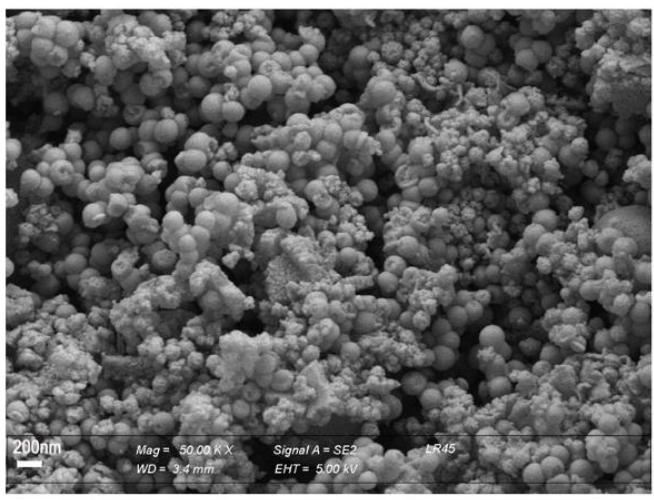

NC loaded with ZS

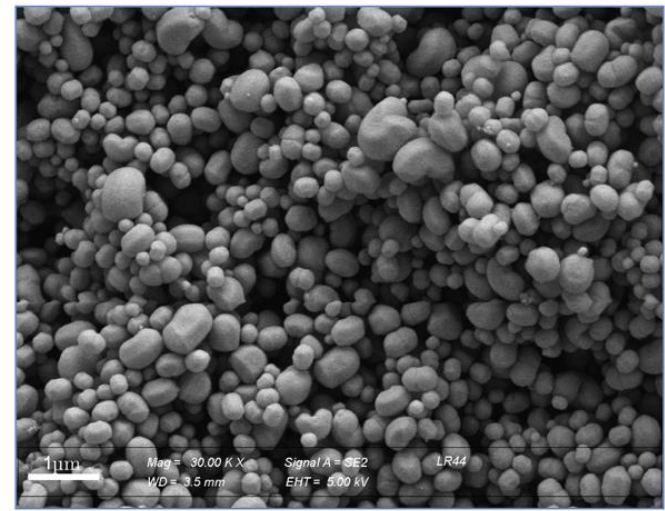

MNP loaded with ZS

Figure 1. Structure of nanocontainers synthetized: (a) Silica Nanocapsule (NC): Scheme, SEM images of NC loaded with Zostera sodium salt (ZS); (b) Mesoporous silica nanoparticles (MNP): Scheme, SEM images of NC loaded with Zostera sodium salt (ZS). For the representation of Silica Nanocapsule and Mesoporous silica nanoparticles loaded with MBT, we refer to Ruggiero et al. [21].

A micellar solution was obtained by combining water, surfactant, and the basic catalyst. Alternatively, MBT or ZS were secondly added by using diethyl ether as the cosolvent. Therefore, an oil-in-water mini-emulsion was created due to the presence of diethyl ether, and the TEOS condensates at the mini-emulsion interface to form the inorganic silica network. The subsequent evaporation of the diethyl ether creates the mesoporosity of the shell.

For the synthesis of silica nanoparticles (MNP), the same reagents were used-except for diethyl ether-and the ammonia solution was substituted by $\mathrm{NaOH}$ aqueous solution. Differently from the previous synthesis, the biocides were inserted directly into the mixture before the formation of the micellar solution. TEOS plays the role of the template since its molecules polymerize around it.

\subsection{In Vitro Tests}

To perform in vitro tests, we collected biofilm materials growing on the Aurelian Walls in Rome, as a monument representative of biodeterioration patterns occurring in the Mediterranean area [13,38,39].

Specifically, we performed a survey on the vertical surfaces of the walls in the northern exposure where the biological growth is widely distributed, and not previously treated by restoration activities. Then, we selected and brushed superficially, employing a sterile lancet and a black humid patina. A part of the collected microorganisms was observed by the optical microscope with an immersion objective at 100-magnification (Olympus BX41, 
Rome, Italy), following the procedures in UNI [40]. Thanks to the analytic keys of Guiry and Guiry [41], we identified the occurring species, which resulted in a mixed community of green algae, cyanobacteria, and meristematic fungi. Then, we cultured the detected species, according to the suggested nutritional and expositive requirements, in a BG-11 liquid media (Sigma-Aldrich) at $25{ }^{\circ} \mathrm{C}$ in conditions of natural sunlight, as previously reported [13]. Indeed, this type of media favored the proliferation of the algal component, and after two months, we obtained an almost pure culture of Chlorococcum sp. that we used as target organisms to test the efficiency of our nanosystems.

We tested eight different situations: the two free biocides (MBT and ZS); the two different nanosystems not loaded with biocides (NC, MNP); the two nanosystems loaded with zosteric sodium salt (NC_ZS; MNP_ZS) and with 2-mercaptobenzothiazole (NC_MBT; MNP_MBT). The nanocontainers were loaded with a concentration of biocide related to the loading capability (respectively, NC_Zs $=2.1 \%$; MNP_ZS $=7.8 \%$; NC_MBT $=10 \%$; MNP_MBT 8.2\%). We tested, following the protocol fine-tuned in Ruggiero et al. [13], $3 \mathrm{mg}$ of nanocontainers not loaded and loaded with the biocide, added to $1 \mathrm{~mL}$ of liquid culture. For the free biocide, we tested a minimum $(1 \mathrm{mg})$ and maximum $(3 \mathrm{mg})$ quantity, emphasizing the concentrations based on those loaded in the nanosystems $(\sim 0.01 \mathrm{mg} / \mathrm{mL})$ and the weight put in $1 \mathrm{~mL}$ of culture $(3 \mathrm{mg})$.

Biocide efficiency was evaluated periodically, after the 1st, 2nd, 4th, 6th, and 8th week, so we filled 40 test tubes for each product tested in each time control. We observed the control and the treated cultures, in triplicate form for each product, under an optical microscope (Zeiss Axioplan 2) equipped with a photo camera (LEICA DFC $450 \mathrm{C}$ ) at 20X magnification in visible and autofluorescent light. Following the methodology of previous works $[10,19,42,43]$, we evaluated the loss of each cell's fluorescence as an indicator of biocidal efficiency. We observed the autofluorescence of cultured microorganisms with multi-channel detection, in blue (450-500 nm), purple (380-450 nm), and green $(500-570 \mathrm{~nm})$ wavelengths $[44,45]$. The photosynthetic microorganisms, in our case green algae, contain chlorophylls, which show autofluorescence at $670-790 \mathrm{~nm}$ (excitation, $594 \mathrm{~nm}$ ) [42-46]. We used multiple channels to observe not only the disappearance of the chlorophyll but also of the other accessory pigments, evaluating the change in chlorophyll fluorescence from red to green until its disappearance. In the monitoring occurring over the weeks, we analyzed the pigment's autofluorescence to discriminate between active cells (the presence of chlorophyll autofluorescence) and inactive/dead cells (between the absence of chlorophyll autofluorescence and complete absence of fluorescence) [42]. In addition to this direct qualitative method to monitor the temporal dynamic of biocidal efficiency, we performed cell counts. We captured the optical image at 20X magnification in visible and fluorescent light. For each product in each week, we observed 3 different optical slides, and for each slide, we captured 3 snapshot images, to have 9 images for each product each week. We analyzed the images through ImageJ software $[47,48]$, and we performed cells counts, discriminating between the total fluorescent cells and the chlorophyll fluorescent cells (red ones). In this way, to normalize the number, we calculated the percentage of cells and the rate of autofluorescence loss.

\section{Results}

\section{Biocidal Efficiency}

The analysis of the three different systems-the free biocides, not-loaded nanocontainers, and loaded nanocontainers-showed multiple differences.

For the free biocide, the optical microscopy images at the 8th week show a higher efficiency of MBT than ZS, which does not highlight evidence of biocidal activity in both concentrations (Figure 2a). Indeed, it is clear in the images of both concentrations of ZS that no fluorescence reduction is evident. Instead, the MBT biocide shows a higher efficiency in $3 \mathrm{mg}$ concentration than $1 \mathrm{mg}$, as expected, even if the chlorophyll's fluorescence has not completely disappeared by the 8 th week. 

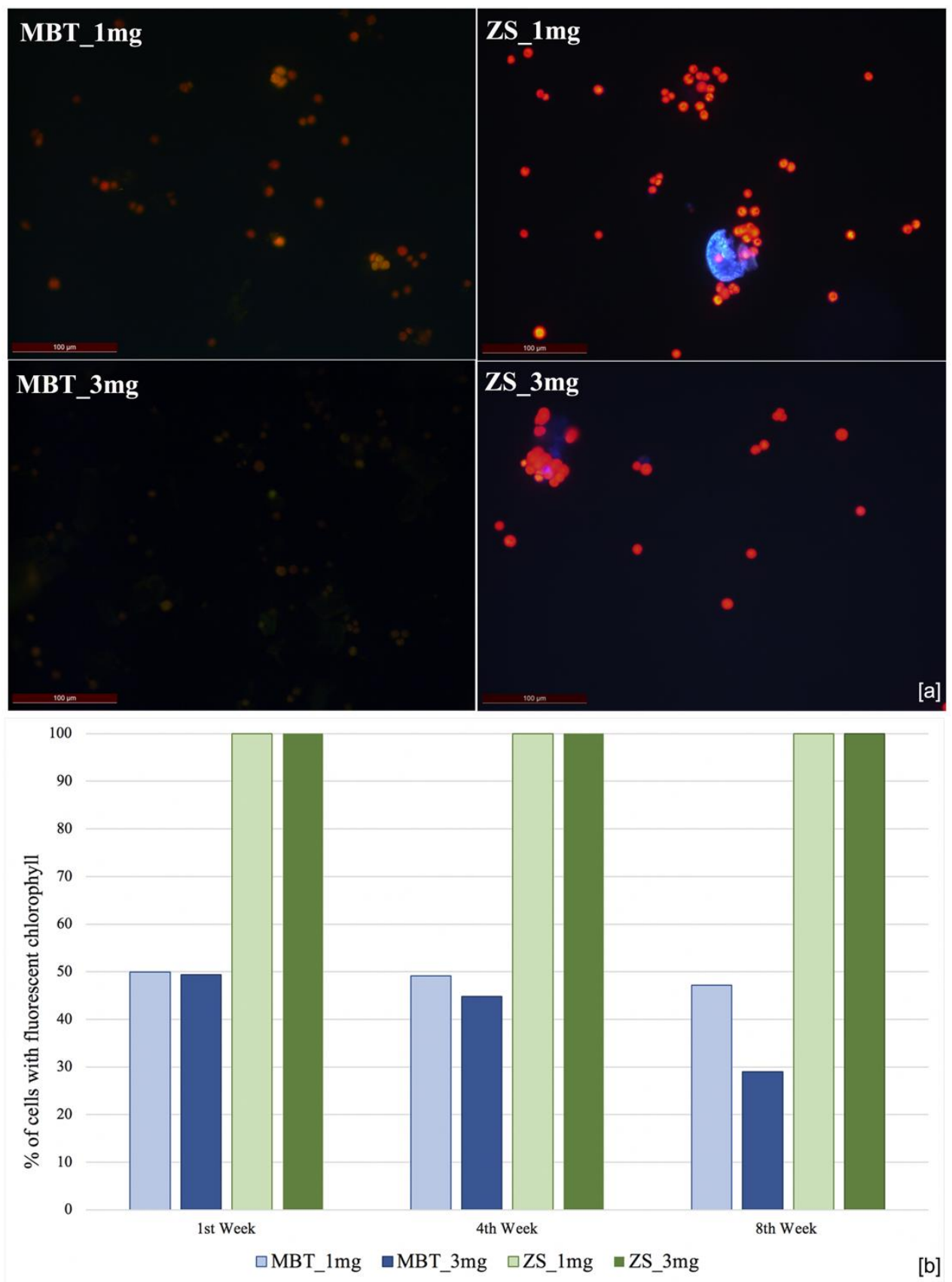

Figure 2. Evaluation of Zostera sodium salt (ZS) and 2-mercaptobenzothiazole (MBT) efficiency applied as free biocides in different concentrations ( $3 \mathrm{mg}$ and $1 \mathrm{mg}$ ). (a) Optical microscope image in blue channel fluorescent light at the 8 th week. The loss of fluorescence of chlorophyll (red) highlights the efficiency of the biocide. (b) Graph of red fluorescence percentage of culture treated with different concentrations of both free biocides. The decrease in fluorescent cells' percentage highlights the efficiency of products.

The quantitative analysis, performed with the cell count, confirms the qualitative data obtained by the optical microscope observation. The graph (Figure 2b) highlights that the vitality of the cells treated with MBT is reduced by about $50 \%$ after the first week for both concentrations but with different rates of reduction, with a rate of reduction of $0.88 \%$ and $4.7 \%$ in the 4 th week, and $2.7 \%$ and $20.37 \%$ in the 8 th week for $1 \mathrm{mg}$ and $3 \mathrm{mg}$, respectively.

All the nanocontainers (loaded and not loaded) present an initial reduction in chlorophyll autofluorescence, which can be noted with a color change of fluorescence from red to green, different to the pure biocide, which, after 1 week, did not show this effect. 
The non-loaded nanosystems highlighted a clear reduction in chlorophyll autofluorescence of the photosynthetic microorganisms already after the first week and, almost complete disappearance of chlorophyll fluorescence after the 6th week. Indeed, the optical image at the 8th week shows the complete disappearance of chlorophyll fluorescence and only a few cells with very low green fluorescence. The quantitative analysis of non-loaded nanocontainers highlighted a very high efficiency rate, reducing the vitality of the cells at about $2 \%$ in only 4 weeks (Figure $3 a$ ).
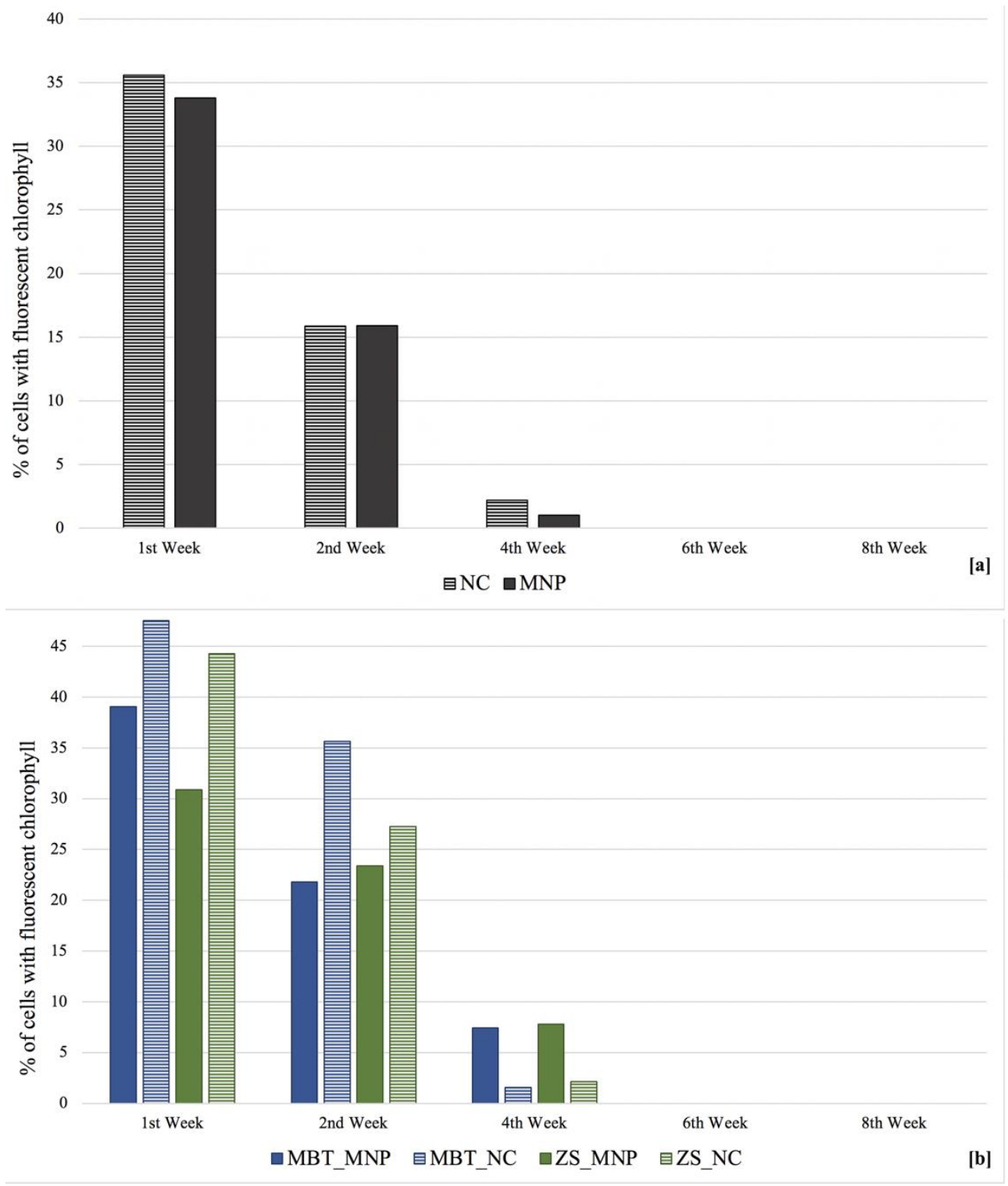

Figure 3. Evaluation of biocide efficiency of nanocontainers not loaded (NC; MNP) and loaded with the biocides (NC_ZS; NC_MBT; MNP_MBT; NC_MBT), where the decrease in fluorescent cells' percentage highlights the efficiency of products. (a) Graph of red fluorescence percentage of culture treated with non-loaded nanocontainers. (b) Graph of red fluorescence percentage of culture treated with loaded nanocontainers.

Finally, the nanosystems loaded with different biocides highlighted a higher efficiency for the mesoporous systems (MNP) than the nanocapsules (NC). Indeed, in the optical images, it is clear that both MBT-NC and ZS-NC at the 8th week show complete disappearance of red fluorescence but a few cells with low green fluorescence, different to MBT-MNP and ZS_MNP that show complete disappearance of fluorescence. 
Moreover, confirming the qualitative data from a quantitative point of view, it is also evident that nanocontainers loaded with the commercial biocide are more efficient than the green product. Indeed, Figure $3 \mathrm{~b}$ shows that in the 4th week, MBT_MNP has a redution rate of $31.63 \%$ in comparison with $23.08 \%$ for ZS-MNP.

Comparing the biocide efficiency of pure biocide with the biocide loaded in the nanosystems, it is highlighted that there is a quantity reduction in biocide used of 10 and $12 \%$, respectively, for MBT-NC and MBT-MNP, and 47.6 and $12.6 \%$, respectively, for ZS-NC and ZS-MNP. This reduction is linked to an efficiency increase of $71 \%$ and $50 \%$, respectively, for $3 \mathrm{mg}$ and $1 \mathrm{mg} \mathrm{MBT}$, and of 100\% for both nanocontainers with ZS.

Finally, the different efficiencies of the non-loaded nanosystems in comparison with the loaded nanosystems are highlighted by the quantitative analyses of green and red fluorescence (Figure 4), which show the complete disappearance of red cells (chlorophylls' activity) at the 6th week, but differential data resulting for the complete disappearance of fluorescence. Indeed, the quantitative comparison between red and green fluorescence analyses shows the MNP system loaded with both biocides (MBT, ZS) at the 8th week gave rise to a complete disappearance of the fluorescent cells, and the same results occurred at the 6th week for the MNP systems loaded with MBT biocide (Figure 4).

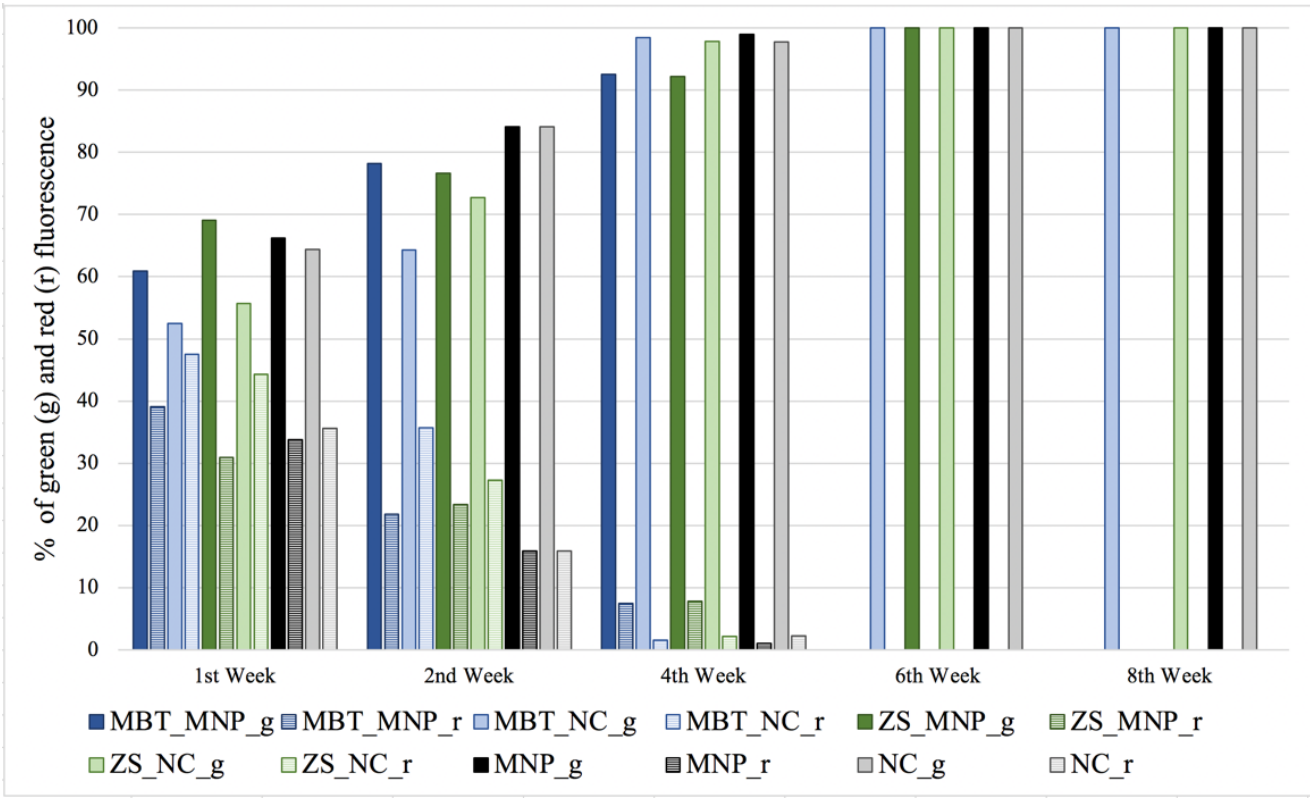

Figure 4. Comparative evaluation between the fluorescence of accessory pigments (green) and the chlorophyll (red) of the nanocontainers not loaded and loaded with biocides. The changing of the cells' fluorescence from red to green and the successive complete disappearance highlights the differential efficiency of products.

\section{Discussion}

The formulation of nanosystems for a multifunctional coating applicable as a preventive tool against the colonization of microorganisms on stone monuments resulted in a real improvement of chemical treatments with biocides [7,49-52]. As previously stressed in the literature, the multifunctional coating in relation to their formulation and functionality can condition the release of antifouling products loaded in nanosystems $[11,13,18,21,53,54]$. In this way, it is therefore important as a first step to analyze the biocide efficacy in a controlled environment before incorporating the nanosystems into the coatings.

Our study showed that both the biocide chemical composition and the differential nanostructures can give rise to a differential efficiency in the antifouling activity against green algae. Indeed, the presence of CTAB (cetyl trimethyl ammonium bromide) as a surfactant gives nanocontainers an unequivocal biocidal activity against algal cells. This result could be expected because this product is commonly used in DNA extraction protocol 
for plants [55]; the negative effect against algal cells seems coherent. The presence of CTAB explains the antifouling activity of the nanosystems in the absence of further biocidal compounds.

However, CTAB is not used as a free biocide due to its toxicity and the possibility of it being released into the environment when directly applied on stone surfaces [56]. According to the EU Regulation [57], CTAB is a cetrimonium bromide $\left(\mathrm{C}_{19} \mathrm{H}_{42} \mathrm{BrN}\right)$ and it is classified in the safety data sheet as toxic for the environment (very toxic to aquatic life with long-lasting effects, Risk Category 1), and for restorer (if ingested and inhaled, Risk Category 4, or irritating to skin or mucous membranes, Risk Category 2/1), but in the same way, it is completely biodegradable both in water and in soil. Moreover, it does not bioaccumulate in organisms. Furthermore, in this context, CTAB is used in the synthesis procedure of nanocontainers and the amount in excess is removed by centrifugation and the application of multifunctional coatings containing the nanocontainers prevents its release into the environment $[19,56,58]$. Therefore, in view of an in situ application, even if residue should remain after washing, its quantity and its entrapment inside the coating would not make it toxic for the environment [19,56-58].

Furthermore, our results highlighted that the biocides used by direct applications (Figure 2), although in much higher quantities than in encapsulated biocide (Figure $3 b$ ), showed lower antifouling activity. In particular, ZS as a free biocide did not show any relevant biocidal activity against the algal cells at the experimented doses. Noteworthy, these data, which are the first on biocidal efficiency against algal cells, showed different results concerning previously reported data on biocidal efficiency against bacterial [37,59-61] and fungal species [61,62], such as in the case of encapsulated product [63,64]. Despite the promising results of previously detected microorganisms, ZS did not show a broad spectrum of biocidal efficiency. Such data can be related to the mechanisms of biocidal activity of this compound. Indeed, the previous studies demonstrate that this compound does not act by killing the microorganisms but by inhibiting their adhesion, blocking the interaction of the microorganisms with the surface [61,63-65].

Furthermore, the different efficiency between NC for the MNP systems highlighted that the second one presents higher efficiency (Figure 3b). This aspect seems to be related to the structure of the nanocontainers [21,22]. Indeed, the self-assembly method for the two nanosystems is different; the mesoporous system presents hexagonally packed cylindric mesopores whereas the nanocapsule presents a core-shell structure (Figure 1). These different structures seem to explain why in the short period, the MNP resulted more efficiently than the NC, since the biocide compounds result in being less trapped and more quickly released [21,22].

Finally, we also observe that different biodeterioration patterns can highly vary, and they form complex communities, resulting from different environmental and edaphic conditions [9,66-68]. Therefore, a biocidal system that is the best for all conditions does not exist. In any case, the establishment of the efficiency of some different nanosystems against one relevant component of biofilm occurring on stone monuments can be considered a significant result. We believe that such a result could be useful in the case of green algae colonization, occurring on stone surfaces showing high humidity values and low solar radiation. Further in situ tests will give new evaluations which will allow wider testing on other occurring organisms, such as cyanobacteria and meristematic fungi, which are not represented by these in vitro tests.

The potential interference of such coatings on stone surfaces was previously preliminarily assessed. Our results showed that the addition of the silica nanocontainers at $0.05 \%$ $(w / v)$ in sol did not change the color of the coating and reduced the formation of cracks after drying [22].

Further promising results could also arise, combining systems with nanostructures and enzymes used for cleaning biological coatings, as shown by the recent literature [69]. 


\section{Conclusions}

The research, even if limited to in vitro tests, with the selection of one widely recurrent genus of green algae as the cultivable microorganism, confirmed the interest of the silica nanosystems coupled with biocides as a potential protective coating for stone monuments. In particular, nanoparticles, synthesized for the formulation of a multifunctional coating, proved better than nanocontainers as being promising tools in the conservation of stone cultural heritage. Enlarging the testing against other components of biological communities occurring on stone monuments, research must move forward to find the best combination between the type of encapsulated biocide and the most efficient nanosystem structure.

Author Contributions: Conceptualization, F.B.; Methodology and Validation, F.B., M.Z.; Formal Analysis and Investigation, F.B.; Writing, F.B., G.C., M.Z., A.S. Funding Acquisition, G.C., A.S. All authors have read and agreed to the published version of the manuscript.

Funding: This research was funded by Regione Lazio, Italy within the "GRAL- GReen And Longlasting stone conservation products" project (n. F85F21001710009) financed in the call " Progetto Gruppi di Ricerca 2020".

Institutional Review Board Statement: This study did not involve animals.

Informed Consent Statement: Informed consent was obtained from all subjects involved in the study.

Acknowledgments: The authors acknowledge The Grant of Excellence Departments, MIUR (ARTICOLO 1, COMMI 314-337 LEGGE 232/2016). The authors acknowledge Ludovica Ruggiero for supporting the synthesis procedure of the silica nanocontainers.

Conflicts of Interest: The authors declare no conflict of interest. The funders had no role in the design of the study; in the collection, analyses, or interpretation of data; in the writing of the manuscript, or in the decision to publish the results.

\section{References}

1. Videla, H.A.; Herrera, L.K. Biodeterioration and weathering effects on rock decay. Corros. Rev. 2004, 22, 341-364. [CrossRef]

2. Caneva, G.; Nugari, M.P.; Salvadori, O. Plant. Biology for Cultural Heritage: Biodeterioration and Conservation; The Getty Conservation Institute: Los Angeles, CA, USA, 2008.

3. Camuffo, D. Microclimate for Cultural Heritage: Measurement, Risk Assessment, Conservation, Restoration, and Maintenance of Indoor and Outdoor Monuments, 3rd ed.; Elsevier: Amsterdam, The Netherlands, 2019.

4. Cappitelli, F.; Villa, F.; Sorlini, C. New environmentally friendly approaches against biodeterioration of outdoor cultural heritage. In Biocolonization of Stone: Middle Missouri Plains Control and Preventive Village Sites Methods, Proceedings of the MCI Workshop Series; Elena Charola, A., Ed.; Smithsonian Contributions to Museum Conservation; Smithsonian Institution Scholarly Press: Washington, DC, USA, 2011; pp. 51-58.

5. Baglioni, P.; Chelazzi, D.; Giorgi, R. Nanotechnologies in the Conservation of Cultural Heritage: A Compendium of Materials and Techniques; Springer: Dordrecht, The Netherlands; Berlin/Heidelberg, Germany; New York, NY, USA; London, UK, 2014. [CrossRef]

6. Serafini, I.; Ciccola, A. Nanotechnologies and Nanomaterials. Nanotechnologies and Nanomaterials for Diagnostic. Conserv. Restor. Cult. Herit. 2019, 325-380. [CrossRef]

7. Tortora, L.; Di Carlo, G.; Mosquera, M.J.; Ingo, G.M. Nanoscience and Nanomaterials for the Knowledge and Conservation of Cultural Heritage. Front. Mater. Sci. 2020, 7, 372-374. [CrossRef]

8. Fidanza, M.R.; Caneva, G. Natural biocides for the conservation of stone cultural heritage: A review. J. Cult. Herit. 2019, 38, 271-286. [CrossRef]

9. Caneva, G.; Nugari, M.P.; Pinna, D.; Salvadori, O. Il Controllo del Degrado Biologico: I Biocidi nel Restauro dei Materiali Lapidei; Nardini Editore: Fiesole, Italy, 1996; p. 151.

10. Pinna, D. Coping with Biological Growth on Stone Heritage Objects: Methods, Products, Applications, and Perspectives; Apple Academic Press: Waretown, NJ, USA, 2017.

11. Kakakhel, M.A.; Wu, F.; Gu, J.D.; Feng, H.; Shah, K.; Wang, W. Controlling biodeterioration of cultural heritage objects with biocides: A review. Int. Biodeterior. Biodegrad. 2019, 143, 104721. [CrossRef]

12. Nugari, M.P.; Pallecchi, P.; Pinna, D. Methodological Evaluation of Biocidal Interference with Stone Minerals—Preliminary Laboratory Tests. In Proceedings of the International RILEM/UNESCO Congress on Conservation of Stone and Other Materials, Paris, France, 29 June-1 July 1993; Thiel, M.J., Ed.; E. \& F. N. Spon: London, UK, 1993; pp. 295-302. 
13. Ruggiero, L.; Bartoli, F.; Fidanza, M.R.; Zurlo, F.; Marconi, E.; Gasperi, T.; Tuti, S.; Crociani, L.; Di Bartolomeo, E.; Caneva, G.; et al. Encapsulation of environmentally-friendly biocides in silica nanosystems for multifunctional coatings. Appl. Surf. Sci. 2020, 514, 145908. [CrossRef]

14. Ruggiero, L.; Fidanza, M.R.; Iorio, M.; Tortora, L.; Caneva, G.; Ricci, M.A.; Sodo, A. Synthesis and characterization of TEOS coating added with innovative antifouling silica nanocontainers and $\mathrm{TiO}_{2}$ nanoparticles. Front. Mater. 2020, 7, 185. [CrossRef]

15. Silva, M.; Rosado, T.; Teixeira, D.; Candeias, A.; Caldeira, A.T. Production of green biocides for cultural heritage. Novel biotechnological solutions. Int. J. Conserv. Sci. 2015, 6, 519-530.

16. Silva, M.; Salvador, C.; Candeias, M.F.; Teixeira, D.; Candeias, A.; Caldeira, A.T. Toxicological assessment of novel green biocides for cultural heritage. Int. J. Conserv. Sci. 2016, 7, 265-272.

17. Rotolo, V.; Barresi, G.; Di Carlo, E.; Giordano, A.; Lombardo, G.; Crimi, E.; Costa, E.; Bruno, M.; Palla, F. Plant extracts as green potential strategies to control the biodeterioration of cultural heritage. Int. J. Conserv. Sci. 2016, 7, 839-846.

18. Dresler, C.; Saladino, M.; Demirbag, C.; Caponetti, E.; Martino, D.F.C.; Alduina, R. Development of controlled release systems of biocides for the conservation of cultural heritage. Int. Biodeterior. Biodegrad. 2017, 125, 150-156. [CrossRef]

19. Kuznetsova, A.; Domingues, P.M.; Silva, T.; Almeida, A.; Zheludkevich, M.L.; Tedim, J.; Ferreira, M.G.S.; Cunha, A. Antimicrobial activity of 2-mercaptobenzothiazole released from environmentally friendly nanostructured layered double hydroxides. J. Appl. Microbiol. 2017, 122, 1207-1218. [CrossRef] [PubMed]

20. Ruggiero, L.; Crociani, L.; Zendri, E.; El Habra, N.; Guerriero, P. Incorporation of the zosteric sodium salt in silica nanocapsules: Synthesis and characterization of new fillers for antifouling coatings. Appl. Surf. Sci. 2018, 439, 705-711. [CrossRef]

21. Ruggiero, L.; Di Bartolomeo, E.; Gasperi, T.; Luisetto, I.; Talone, A.; Zurlo, F.; Peddis, D.; Ricci, M.A.; Sodo, A. Silica nanosystems for active antifouling protection: Nanocapsules and mesoporous nanoparticles in controlled release applications. J. Alloys Compd. 2019, 798, 144-148. [CrossRef]

22. Ruggiero, L.; Sodo, A.; Cestelli-Guidi, M.; Romani, M.; Sarra, A.; Postorino, P.; Ricci, M.A. Raman and ATR FT-IR investigations of innovative silica nanocontainers loaded with a biocide for stone conservation treatments. Microchem. J. 2020, 155, 104766. [CrossRef]

23. Arreche, R.; Vázquez, P. Green biocides to control biodeterioration in materials science and the example of preserving World Heritage Monuments. Curr. Opin. Green Sustain. Chem. 2020, 100359. [CrossRef]

24. Palla, F. Biotechnology and Cultural Heritage Conservation. In Heritage; IntechOpen: London, UK, 2020. [CrossRef]

25. McCusker, L.; Liebau, F.; Engelhardt, G. Nomenclature of structural and compositional characteristics of ordered microporous and mesoporous materials with inorganic hosts (IUPAC Recommendations 2001). Pure Appl. Chem. 2009, 73, 381e394. [CrossRef]

26. Mattos, B.D.; Rojas, O.J.; Magalhães, W.L. Biogenic silica nanoparticles loaded with neem bark extract as green, slow-release biocide. J. Clean. Prod. 2017, 142, 4206-4213. [CrossRef]

27. Campanella, L.; Angeloni, R.; Cibin, F.; Dell'Aglio, E.; Grimaldi, F.; Reale, R.; Vitali, M. Capsulated essential oil in gel spheres for the protection of cellulosic cultural heritage. Nat. Prod. Res. 2021, 35, 116-123. [CrossRef] [PubMed]

28. Chen, H.; He, J.; Tang, H.; Yan, C. Porous silica nanocapsules and nanospheres: Dynamic self-assembly synthesis and application in controlled release. Chem. Mater. 2008, 20, 5894-5900. [CrossRef]

29. Popat, A.; Liu, J.; Hu, Q.; Kennedy, M.; Peters, B.; Lu, G.Q.; Qiao, S.Z. Adsorption and release of biocides with mesoporous silica nanoparticles. Nanoscale 2012, 4, 970e975. [CrossRef]

30. Chan, A.C.; Bravo Cadena, M.; Townley, H.E.; Fricker, M.D.; Thompson, I.P. Effective delivery of volatile biocides employing mesoporous silicates for treating biofilms. J. R. Soc. Interface 2017, 14, 20160650. [CrossRef]

31. European Parliament. Directive of the European Parliament and of the council of 16 February 1998 concerning the placing of biocidal products on the market. Off. J. Eur. Commun. 1998, L123, 1-63.

32. Orlita, A. Microbial biodeterioration of leather and its control: A review. Int. Biodeterior. Biodegrad. 2004, 53, 157-163. [CrossRef]

33. Nascimbene, J.; Salvadori, O. Lichen recolonization on restored calcareous statues of three Venetian villas. Int. Biodeterior. Biodegrad. 2008, 62, 313-318. [CrossRef]

34. Jendresen, C.B.; Nielsen, A.T. Production of zosteric acid and other sulfated phenolic biochemicals in microbial cell factories. Nat. Commun. 2019, 10, 1-10. [CrossRef]

35. Daidone, G.; Maggio, B.; Schillaci, D. Salicylanilide and its heterocyclic analogues. A comparative study of their antimicrobial activity. Pharmazie 1990, 45, 441-442. [PubMed]

36. Franchini, C.; Muraglia, M.; Corbo, F.; Florio, M.A.; Di Mola, A.; Rosato, A.; Matucci, R.; Nesi, M.; van Bambeke, F.; Vitali, C. Synthesis and Biological Evaluation of 2-Mercapto-1, 3-benzothiazole Derivatives with Potential Antimicrobial Activity. Arch. Pharm. 2009, 342, 605-613. [CrossRef]

37. Zhang Newby, B.; Cutright, T.; Barrios, C.A.; Xu, Q. Zosteric acid-An effective antifoulant for reducing fresh water bacterial attachment on coatings. JCT Res. 2006, 3, 69-70.

38. Caneva, G.; De Marco, G.; Dinelli, A.; Vinci, M. The wall vegetation of the roman archaeological areas. Sci. Technol. Cult. Herit. 1992, 1, 217-226.

39. Cappitelli, F.; Villa, F. Novel Antibiofilm Non-Biocidal Strategies. In Microorganisms in the Deterioration and Preservation of Cultural Heritage; Edith, J., Ed.; Springer: Berlin, Germany, 2021; p. 117. [CrossRef]

40. UNI 10923. Beni culturali: Materiali lapidei naturali ed artificiali. In Allestimento di Preparati Biologici per L'osservazione al Microscopio Ottico; UNI: Milano, Italy, 2001. 
41. Guiry, M.D.; Guiry, G.M. AlgaeBase Version 4.2. World-Wide Electronic Publication; National University of Ireland: Maynooth, Ireland, 2007. Available online: http:/ / www.algaebase.org (accessed on 2 February 2020).

42. Ramírez, M.; Hernández-Mariné, M.; Novelo, E.; Roldán, M. Cyanobacteria-containing biofilms from a Mayan monument in Palenque, Mexico. Biofouling 2010, 26, 399-409. [CrossRef]

43. Hsieh, P.; Pedersen, J.Z.; Bruno, L. Photoinhibition of cyanobacteria and its application in cultural heritage conservation. Photochem. Photobiol. 2014, 90, 533-543. [CrossRef]

44. García-Plazaola, J.I.; Fernández-Marín, B.; Duke, S.O.; Hernández, A.; López-Arbeloa, F.; Becerril, J.M. Autofluorescence: Biological functions and technical applications. Plant Sci. 2015, 236, 136-145. [CrossRef]

45. Donaldson, L. Autofluorescence in plants. Molecules 2020, 25, 2393. [CrossRef] [PubMed]

46. Lamb, J.J.; Røkke, G.; Hohmann-Marriott, M.F. Chlorophyll fluorescence emission spectroscopy of oxygenic organisms at 77 K. Photosynthetica 2018, 56, 105-124. [CrossRef]

47. Abràmoff, M.D.; Magalhães, P.J.; Ram, S.J. Image processing with ImageJ. Biophotonics Int. 2004, 11, 36-42.

48. Rasband, W.S. ImageJ; US National Institutes of Health: Bethesda, MD, USA, 1997.

49. Colangiuli, D.; Calia, A.; Bianco, N. Novel multifunctional coatings with photocatalytic and hydrophobic properties for the preservation of the stone building heritage. Constr. Build. Mater. 2015, 93, 189-196. [CrossRef]

50. La Russa, M.F.; Ruffolo, S.A.; Rovella, N.; Belfiore, C.M.; Palermo, A.M.; Guzzi, M.T.; Crisci, G.M. Multifunctional TiO 2 coatings for cultural heritage. Prog. Org. Coat. 2012, 74, 186-191. [CrossRef]

51. Ruffolo, S.A.; La Russa, M.F. Nanostructured coatings for stone protection: An overview. Front. Mater. Sci. 2019, 6, 147. [CrossRef]

52. Zuena, M.; Ruggiero, L.; Della Ventura, G.; Bemporad, E.; Ricci, M.A.; Sodo, A. Effectiveness and Compatibility of Nanoparticle Based Multifunctional Coatings on Natural and Man-Made Stones. Coatings 2021, 11, 480. [CrossRef]

53. Becerra, J.; Mateo, M.; Ortiz, P.; Nicolás, G.; Zaderenko, A.P. Evaluation of the applicability of nano-biocide treatments on limestones used in cultural heritage. J. Cult. Herit. 2019, 38, 126-135. [CrossRef]

54. Castaldo, R.; de Luna, M.S.; Siviello, C.; Gentile, G.; Lavorgna, M.; Amendola, E.; Cocca, M. On the acid-responsive release of benzotriazole from engineered mesoporous silica nanoparticles for corrosion protection of metal surfaces. J. Cult. Herit. 2020, 44, 317-324. [CrossRef]

55. Rogers, S.O.; Bendich, A.J. Extraction of DNA from plant tissues. In Plant Molecular Biology Manual; Springer: Dordrecht, The Netherlands, 1989; pp. 73-83. [CrossRef]

56. Ray, P.C.; Yu, H.; Fu, P.P. Toxicity and environmental risks of nanomaterials: Challenges and future needs. J. Environ. Sci. Health C 2009, 27, 1-35. [CrossRef] [PubMed]

57. EU Regulation 1907/2006: Registration, Evaluation, Authorisation and Restriction of Chemicals (REACH). Available online: https: / / osha.europa.eu/en/legislation/directives/regulation-ec-no-1907-2006-of-the-european-parliament-and-of-the-council (accessed on 23 July 2021).

58. Pastoriza-Santos, I.; Pérez-Juste, J.; Liz-Marzán, L.M. Silica-coating and hydrophobation of CTAB-stabilized gold nanorods. Chem. Mater. 2006, 18, 2465-2467. [CrossRef]

59. Todd, J.S.; Zimmerman, R.C.; Crews, P.; Alberte, R.S. The AF activity of natural and synthetic phenolic-acid sulfate esters. Phytochemistry 1993, 34, 401-404. [CrossRef]

60. Villa, F.; Remelli, W.; Forlani, F.; Vitali, A.; Cappitelli, F. Altered expression level of Escherichia coli proteins in response to treatment with the antifouling agent zosteric acid sodium salt. Environ. Microbiol. 2012, 14, 1753-1761. [CrossRef]

61. Vilas-Boas, C.; Sousa, E.; Pinto, M.; Correia-da-Silva, M. An antifouling model from the sea: A review of 25 years of zosteric acid studies. Biofouling 2017, 33, 927-942. [CrossRef]

62. Villa, F.; Pitts, B.; Stewart, P.S.; Giussani, B.; Roncoroni, S.; Albanese, D.; Giordano, C.; Tunesi, M.; Cappitelli, F. Efficacy of zosteric acid sodium salt on the yeast biofilm model Candida albicans. Microb. Ecol. 2011, 62, 584. [CrossRef]

63. Geiger, T.; Delavy, P.; Hany, R.; Schleuniger, J.; Zinn, M. Encapsulated zosteric acid embedded in poly [3-hydroxyalkanoate] coatings-Protection against biofouling. Polym. Bull. 2004, 52, 65-72. [CrossRef]

64. Boopalan, M.; Sasikumar, A. Studies on biocide free and biocide loaded zeolite hybrid polymer coatings on zinc phosphated mild steel for the protection of ships hulls from biofouling and corrosion. Silicon 2011, 3, 207-214. [CrossRef]

65. Cattò, C.; Dell'Orto, S.; Villa, F.; Villa, S.; Gelain, A.; Vitali, A.; Marzano, V.; Baroni, S.; Forlani, F.; CAppitelli, F. Unravelling the Structural and Molecular Basis Responsible for the Anti-Biofilm Activity of Zosteric Acid. PLoS ONE 2015, 10, e0131519. [CrossRef] [PubMed]

66. Caneva, G.; Salvadori, O.; Ricci, S.; Ceschin, S. Ecological analysis and biodeterioration processes over time at the Hieroglyphic Stairway in the Copán (Honduras) archaeological site. Plant Biosyst. 2005, 139, 295-310. [CrossRef]

67. Caneva, G.; Bartoli, F.; Savo, V.; Futagami, Y.; Strona, G. Combining statistical tools and ecological assessments in the study of biodeterioration patterns of stone temples in Angkor (Cambodia). Sci. Rep. 2016, 6, 1-8. [CrossRef] [PubMed]

68. Municchia, A.C.; Bartoli, F.; Taniguchi, Y.; Giordani, P.; Caneva, G. Evaluation of the biodeterioration activity of lichens in the Cave Church of Üzümlü (Cappadocia, Turkey). Int. Biodeterior. Biodegrad. 2018, 127, 160-169. [CrossRef]

69. Valentini, F.; Diamanti, A.; Carbone, M.; Bauer, E.M.; Palleschi, G. New cleaning strategies based on carbon nanomaterials applied to the deteriorated marble surfaces: A comparative study with enzyme-based treatments. App. Surf. Sci. 2012, 258, 5965-5980. [CrossRef] 